\title{
SIFAT FISIKO KIMIA MINYAK KILEMO (Litsea cubeba) ASAL KUNINGAN, JAWA BARAT
}

\author{
(Physico-Chemical Properties of Essential Oil of Litsea cubeba (Kilemo) \\ Originated from Kuningan, West Java)
}

Oleh/By :

Zulnely, Umi Kulsum \& Ahmad Junaedi

\begin{abstract}
Forest in Indonesia is endowed with particular plant species that grow and produce essential oil, among which is kilemo (Litsea cubeba). Almost all parts of kilemo plants originated from Kuningan, West Java could produced essential oil. The distillation employed two methods, i.e. cohobation and steaming which consecutively lasted for 6 and 8 hours.

The results revealed that distillation with 8 hour steaming afforded the highest essential oil yield. Further, the yield of essential oil distilled from kilemo leaves was visually higher than that from kilemo bark. From the physical and chemical analiysis on essential oil, it turned out that spesific gravity, optical rotation, acid number, and particular chemical components in oil from the leaves visually were not similiar with those from the bark. Meanwhile, no significant differences in refractive index and solubility in alcohol occured between oils from the bark and the leaves.
\end{abstract}

Keywords: Kilemoplants, essential kilemo oil, distillation, physico-chemicalproperties

\begin{abstract}
ABSTRAK
Hutan di Indonesia kaya dengan jenis tumbuhan penghasil minyak atsiri, salah satunya adalah tumbuhan kilemo (Litsea cubeba). Hampir semua bagian tumbuhan kilemo bisa menghasilkan minyak atsiri.

Pada penelitian ini dilakukan penyulingan terhadap bagian daun dan kulit batang tumbuhan kilemo yang berasal dari Kuningan, Jawa Barat. Penyulingan dilakukan dengan metode kukus dan rebus, serta waktu penyulingan 6 dan 8 jam.

Hasil penyulingan menunjukkan bahwa rendemen minyak tertinggi dihasilkan dari penyulingan daun yang disuling dengan metode kukus selama $8 \mathrm{jam}$. Rendemen minyak dari daun secara visual lebih tinggi bila dibandingkan dengan rendemen minyak dari kulit batang. Dari analisis minyak diperoleh sifat berat jenis, putaran optik, bilangan asam, bilangan ester dan komponen kimia secara visual berbeda antara minyak dari daun dan minyak dari kulit batang. Sedangkan indeks bias dan kelarutan dalam alkohol kedua minyak dari daun maupun dari kulit batang memiliki sifat yang sama.
\end{abstract}

Kata kunci : Tumbuhan kilemo, minyak kilemo, penyulingan, sifat fisiko kimia 


\section{PENDAHULUAN}

Hutan di Indonesia kaya dengan jenis tumbuhan penghasil minyak atsiri yang mempunyai prospek sangat baik sebagai komoditi ekspor Indonesia. Salah satu tumbuhan penghasil minyak atsiri ini adalah tumbuhan kilemo (Litsea cubeba).

Tumbuhan Litsea cubeba di Jawa Tengah dikenal dengan nama krangean, di Sumatera Utara dengan nama antarasa, sedangkan di daerah Jawa Barat dikenal dengan nama kilemo. Tumbuhan ini termasuk famili Lauraceae, yang merupakan pohon perdu dengan diameter batang 6 - $20 \mathrm{~cm}$ serta tinggi pohon 5 - 12 meter. Penyebaran tumbuhan kilemo di Indonesia meliputi daerah Jawa, Kalimantan dan Sumatera. Tumbuhan kilemo di pulau Jawa banyak dijumpai di daerah dengan ketinggian 230 - $700 \mathrm{~m}$ di atas permukaan laut, terutama di daerah lereng gunung (Heyne, 1987).

Manfaat dari minyak kilemo sangat banyak terutama untuk industri farmasi, wangiwangian, bahan tambahan makanan dan minuman, bahan sabun dan bahan pencampur vitamin yang larut dalam lemak antara lain vitamin $A$ dan $D$.

Hampir semua bagian tumbuhan kilemo dapat menghasilkan minyak atsiri, tetapi yang paling banyak dihasilkan dari bagian daun, kulit batang dan buah. Penelitian terdahulu mengenai penyulingan daun kilemo kering sempurna asal Sukabumi menghasilkan minyak atsiri sebanyak 7,9\%. Mutu dan kualitas minyak atsiri bisa ditentukan dari sifat fisiko kimia minyaknya (Rusli, dkk., 1987). Adapun penelitian ini bertujuan untuk menganalisis sifat fisiko kimia hasil penyulingan daun dan kulit batang tumbuhan kilemo yang berasal dari Kuningan, Jawa Barat. Diharapkan hasil penelitian ini memperkaya dasar pengembangan pemanfaatan tumbuhan kilemo di Indonesia.

\section{BAHAN DAN METODE PENELITIAN}

Bahan penelitian berupa daun dan kulit batang tumbuhan kilemo yang diperoleh dari kawasan gunung Cireme, Kuningan, Jawa Barat. Untuk memperoleh minyak kilemo dilakukan penyulingan daun dan kulit batangnya. Penyulingan ini menggunakan sistem rebus dan kukus dengan waktu penyulingan 6 jam dan 8 jam. Minyak kilemo yang diperoleh dari penyulingan ini di analisis sifat fisiko kimia dan analisis komponen kimia minyak. Analisis sifat fisiko kimia minyak kilemo yang dilakukan adalah berat jenis, indek bias, putaran optik, kelarutan dalam alkohol, bilangan ester dan bilangan asam sesuai dengan prosedur Boedhowie dan Sri Pranggono (1983). Sedangkan analisis komponen kimia dilakukan dengan metode gas kromatografi. Alat gas kromatografi yang digunakan merk Hitachi 267/70 dengan kondisi kolom carbowax panjang 25 meter, suhu kolom oven $60-200^{\circ} \mathrm{C}$, peningkatan suhu $3^{\circ} \mathrm{C}$ per menit, detektor ionisasi nyala dengan suhu $250^{\circ} \mathrm{C}$, volume injektor 0,21 dengan suhu injek $220^{\circ} \mathrm{C}$ dan gas pembawa nitrogen (N2). Perhitungan persentasi setiap komponen berdasarkan metode normalisasi tanpa faktor koreksi. 


\section{HASIL DAN PEMBAHASAN}

\section{A. Rendemen}

Rendemen minyak hasil penyulingan daun dan kulit batang tumbuhan kilemo tercantum pada Tabel 1. Dari hasil penyulingan terlihat bahwa rendemen minyak hasil penyulingan daun secara statistik lebih tinggi bila dibandingkan dengan rendemen minyak dari penyulingan kulit batang. Hasil analisis juga menunjukkan bahwa rendemen minyak dipengaruhi oleh bahan yang disuling (Tabel 2). Rendemen minyak tertinggi dari penyulingan daun maupun kulit batang diperoleh pada kondisi penyulingan dengan metode kukus dan waktu penyulingan 8 jam. Pada kondisi ini rendemen minyak dari daun sebesar 5.4\%, sedangkan rendemen minyak dari kulit batang sebesar $1.55 \%$.

Tabel1. Rendemen hasil penyulingan daun dan kulit batang tumbuhan kilemo (Litsea cubeba)

Table 1. Yield of kilemo oil distilled from leaves and bark of kilemo (Litsea cubeba)

\begin{tabular}{|l|l|c|c|}
\hline Bahan yang disuling & Metode penyulingan & \multicolumn{2}{|c|}{ Waktu penyulingan (Distillation time)* } \\
\cline { 3 - 4 } (Material distilled) & (Distillation method) & 6 jam (hours) & 8 jam (hours) \\
\hline Daun (Leaf) & Kukus (Steam) & $4.05 \%$ & $5.40 \%$ \\
& Rebus (Cohobation) & $4.30 \%$ & $4.65 \%$ \\
\hline Kulit batang & Kukus (Steam) & $1.20 \%$ & $1.55 \%$ \\
(Stem bark) & Rebus (Cobobation) & $1.00 \%$ & $1.05 \%$ \\
\hline
\end{tabular}

Keterangan (Remark) :* Rendemen rata-rata dari dua kali penyulingan (Average yield value of two distillation trials)

Tabe1 2. Ringkasan sidik ragam rendemen minyak kilemo

Table 2. Summarized anlysis of variance on yield of kilemo oil

\begin{tabular}{|l|c|c|}
\hline \multicolumn{1}{|c|}{ Sumber keragaman (Sources of variation) } & $\mathrm{db}(\mathrm{df})$ & F-hitung (F-Calc) \\
\hline Bahan yang disuling (Material distilled) (A) & 1 & $78.85^{* *}$ \\
Metode penyulingan (Distillation method) (B) & 1 & 2.31 \\
Waktu penyulingan (Distillation duration) (C) & 1 & 0.66 \\
Interaksi (Interaction) : & 1 & \\
A x B & 1 & 0.36 \\
A x C & 1 & 0.33 \\
B x C & 1 & 2.53 \\
A x B x C & 1.53 \\
\hline
\end{tabular}

Keterangan (Remarks) : ** Berpengaruh sangat nyata (Highly significant) 
Tabe13. Hasil analisa sifat fisiko kimia minyak kilemo

Table 3. Result of physico-chemical analysis on kilemo oil

\begin{tabular}{|c|c|c|c|c|c|}
\hline \multirow[t]{2}{*}{ Sifat (Properties) } & \multirow[t]{2}{*}{$\begin{array}{l}\text { Metode penyulingan } \\
\text { (Distillation method) }\end{array}$} & \multicolumn{2}{|c|}{$\begin{array}{l}\text { Waktu penyulingan daun } \\
\text { (Distillation time of leave.) }\end{array}$} & \multicolumn{2}{|c|}{$\begin{array}{c}\text { Waktu penyulingan kulit } \\
\text { batang (Distillation time of } \\
\text { stem bark) }\end{array}$} \\
\hline & & 6 jam (hours) & 8 jam (hours) & $6 \mathrm{jam}$ (hours) & 8 jam (hours) \\
\hline \multirow{9}{*}{$\begin{array}{l}\text { Bobot jenis (Specific gravity), } \\
25 / 25^{\circ} \mathrm{C} \\
\text { Indeks bias (Refractive index) } \\
\text { Putaran optik (Optical } \\
\text { rotation) } \\
\text { Kelarutan dalam ethanol } \\
\text { (Solubility on ethanol) } \\
\text { Bilangan asam (Acid value) }\end{array}$} & Rebus (Steam) & 0.9082 & 0.9081 & 0.8891 & 0.8895 \\
\hline & Kukus (Cobobation) & 0.9037 & 0.9039 & 0.8865 & 0.8869 \\
\hline & Rebus (Steam) & 1.4630 & 1.4624 & 1.4612 & 1.4620 \\
\hline & Kukus (Cobobation) & 1.4627 & 1.4617 & 1.4607 & 1.4667 \\
\hline & Rebus (Steam) & $-18^{0} 18^{1}$ & -170 & $-16^{0} 37^{1}$ & $-18^{0} 29^{1}$ \\
\hline & Kukus (Cohobation) & $-20^{0} 30^{1}$ & $-20^{0} 24^{1}$ & $-18^{0} 54^{1}$ & $-18^{045^{1}}$ \\
\hline & Rebus (Steam) & $1: 1$ & 1:1 & 1:1 & 1:1 \\
\hline & Kukus (Cohobation) & $1: 1$ & $1: 1$ & 1:1 & 1:1 \\
\hline & Rebus (Steam) & 0.42 & 1.03 & 1.64 & 1.81 \\
\hline \multirow[t]{3}{*}{ Bilangan ester (Ester value) } & Kukus (Cohobation) & 1.23 & 1.72 & 3.58 & 4.83 \\
\hline & Rebus (Steam) & 25.79 & 31.32 & 17.35 & 17.85 \\
\hline & Kukus (Cohobation) & 32.02 & 31.30 & 20.86 & 16.63 \\
\hline
\end{tabular}

\section{B. Berat Jenis}

Secara visual hasil analisis minyak kilemo menunjukan bahwa berat jenis minyak dari daun lebih tinggi bila dibandingkan minyak dari kulit batang. Berat jenis minyak dari daun rata-rata besarnya 0.9058 , sedangkan berat jenis minyak dari kulit batang besarnya 0.8880 . Menurut Kataren (1997), berat jenis minyak atsiri yang berasal dari famili Lauraceae umumnya sebesar 0.696-1.0888. Besarnya nilai berat jenis ini termasuk golongan kriteria minyak atsiri bermutu baik. Melihat hal tersebut maka minyak kilemo asal Kuningan Jawa Barat berdasarkan berat jenis termasuk minyak atsiri bermutu baik. Dari hasil penelitian terdahulu terlihat bahwa besarnya berat jenis suatu minyak bisa dipengaruhi oleh jenis dan jumlah komponen kimia dalam minyak, semakin banyak komponen kimia dalam minyak maka semakin tinggi berat jenisnya (Wiyono, dkk., 2000).

Dari hasil analisis komponen kimia minyak kilemo (Tabel 4 dan Tabel 5), diperoleh bahwa jumlah kadar kandungan komponen utama minyak dari daun secara visual lebih tinggi bila dibandingkan dengan minyak dari kulit batang. Hal ini yang menyebabkan berat jenis minyak dari daun lebih tinggi bila dibandingkan minyak dari kulit batang seperti yang dilaporkan Wiyono, dkk., 2000.

\section{Indeks Bias}

Hasil analisa minyak kilemo menunjukan bahwa indeks bias minyak dari daun secara visual besarnya hampir sama dengan indeks bias minyak kilemo dari kulit batang. Besarnya indeks bias minyak kilemo ini rata-rata 1.4625. Nilai indeks bias minyak ini bisa dipergunakan untuk menentukan tingkat kemurnian suatu minyak atsiri, oleh karena itu maka minyak kilemo pada penelitian ini mempunyai tingkat kemurnian yang hampir sama. Hal ini sesuai dengan pendapat peneliti terdahulu seperti Jhun (1992) yang menjelaskan bahwa minyak atsiri yang mempunyai tingkat kemurnian hampir sama berarti seluruh sifat fisikanya relatif hampir sama terutama di bagian pohon dalam spesies yang sama. 
Tabe14. Hasil analisis komponen kimia minyak kilemo dari daun Table 4. Result of chemical analysis on kilemo oil from leaves

\begin{tabular}{|c|c|c|c|c|}
\hline \multirow[t]{2}{*}{$\begin{array}{c}\text { Komponen kimia (Chemical } \\
\text { compound), } \% *\end{array}$} & \multicolumn{2}{|c|}{$\begin{array}{c}\text { Waktu penyulingan sistem } \\
\text { kukus (Distillation time for } \\
\text { cohobation method) }\end{array}$} & \multicolumn{2}{|c|}{$\begin{array}{l}\text { Waktu penyulingan sistem } \\
\text { rebus (Distillation time for } \\
\text { steaming method) }\end{array}$} \\
\hline & 6 jam (bours) & 8 jam (hours) & 6 jam (hours) & 8 jam (hours) \\
\hline $\begin{array}{l}\text { Kadar Sineol } \\
\text { (Cineol content) }\end{array}$ & 56.29 & 56.61 & 60.77 & 63.29 \\
\hline $\begin{array}{l}\text { Kadar Sitronellol } \\
\text { (Citronellol content) }\end{array}$ & 11.45 & 12.28 & 9.38 & 9.58 \\
\hline$\alpha$-pinen & 4.94 & 5.09 & 4.08 & 4.30 \\
\hline $\begin{array}{l}(\alpha \text {-pinen content }) \\
\beta \text {-pinen } \\
(\beta \text {-pinen content })\end{array}$ & 14.54 & 15.29 & 12.55 & 11.09 \\
\hline
\end{tabular}

Keterangan (Remark): *Berdasarkan luas puncak (Based on the peak area)

Tabe15. Hasil analisis komponen kimia minyak kilemo dari kulit batang Table 5. Result of chemical analysis on kilemo oil from stem bark

\begin{tabular}{|l|c|c|c|c|}
\hline \multirow{2}{*}{$\begin{array}{c}\text { Komponen kimia } \\
\text { (Chemical compound), \%* }\end{array}$} & \multicolumn{2}{|c|}{$\begin{array}{c}\text { Waktu penyulingan sistem } \\
\text { kukus (Distillation time for } \\
\text { cohobation method) }\end{array}$} & $\begin{array}{c}\text { Waktu penyulingan sistem } \\
\text { rebus (Distillation time for } \\
\text { steaming method) }\end{array}$ \\
\cline { 2 - 5 } & 6 jam (hours) & 8 jam (hours) & 6 jam (hours) & 8 jam (hours) \\
\hline $\begin{array}{l}\text { Kadar Sineol } \\
\text { (Cineol content) } \\
\text { Kadar Limonen } \\
\text { (Limonen content) }\end{array}$ & 19.92 & 13.29 & 15.83 & 15.04 \\
$\begin{array}{l}\text { Kadar Sitronellol } \\
\text { Sitronellol content) }\end{array}$ & 15.09 & 14.34 & 17.65 & 19.19 \\
$\begin{array}{l}\text { Kadar Sitronellal } \\
\text { (Sitronellal content) }\end{array}$ & 3.88 & 3.18 & 2.89 & 3.83 \\
\hline
\end{tabular}

Keterangan (Remark) : *Berdasarkan luas puncak (Based on the peak area)

\section{Putaran Optik}

Putaran optik merupakan kemampuan minyak atsiri untuk memutar bidang polarisasi cahaya. Hasil analisa putaran optik minyak kilemo menunjukkan bahwa metode penyulingan dan jenis bahan yang disuling secara visual mempunyai putaran optik yang berbeda.

Putaran optik minyak kilemo dari daun yang disuling dengan metode kukus besarnya $20^{\circ} 27^{\prime}$, sedangkan yang disuling dengan metode rebus $-17^{\circ} 39^{\prime}$, sementara untuk minyak kilemo yang bersal dari kuit batang disuling dengan metode kukus besarnya $-18^{\circ} 33^{\prime}$ dan yang disuling dengan metode rebus besarnya $-16^{\circ} 33^{\prime}$ Perbedaan putaran optik minyak kilemo ini mungkin disebabkan karena perbedaan tekanan uap pada proses penyulingan. Tingginya 
tekanan uap menyebabkan komponen-komponen minyak yang mempunyai kemampuan memutar bidang polarisasi kearah kanan akan banyak berubah atau terurai sehingga akibatnya putaran optik minyak menjadi kecil (Besari, dkk., 1982).

\section{E. Kelarutan dalam Alkohol}

Kelarutan dalam alkohol merupakan nilai perbandingan banyaknya minyak atsiri yang larut sempurna dengan pelarut alkohol. Setiap minyak atsiri mempunyai nilai kelarutan dalam alkohol yang spesifik, sehingga sifat ini bisa digunakan untuk menentukan suatu kemurnian minyak atsiri.

Dari analisis diperoleh bahwa minyak kilemo dari hasil penyulingan daun maupun kulit batang mempunyai nilai kelarutan dalam alkohol $1: 1$.

\section{F. Bilangan Asam}

Bilangan asam pada minyak atsiri menandakan adanya kandungan asam organik pada minyak tersebut. Asam organik pada minyak atsiri bisa terdapat secara alamiah. Nilai bilangan asam dapat digunakan untuk menentukan kualitas minyak (Kataren, 1985).

Hasil analisis minyak kilemo menunjukkan bahwa minyak kilemo dari kulit batang yang disuling dengan metode kukus secara visual mempunyai bilangan asam tertinggi, sedangkan minyak kilemo dari daun yang disuling dengan metode rebus mempunyai bilangan asam terendah. Besarnya bilangan asam minyak kilemo dari daun yang disuling dengan metode kukus adalah 1.22 dan yang disuling dengan metode rebus 0.72 sedangkan untuk minyak kilemo dari kulit batang yang disuling dengan metode kukus besarnya 4.20, dan yang disuling dengan metode rebus 1.72. Adanya perbedaan nilai bilangan asam minyak kilemo hasil penyulingan daun dan kulit batang disebabkan karena perbedaan kandungan senyawa asam pada minyak. Sedangkan perbedaan nilai bilangan asam minyak kilemo yang disuling dengan sistem kukus dan rebus, kemungkinan disebabkan karena terjadi proses oksidasi pada waktu penyulingan dengan sistem kukus.

\section{G. Bilangan Ester}

Bilang ester merupakan banyaknya jumlah alkali yang diperlukan untuk penyabunan ester. Adanya bilangan ester pada minyak dapat menandakan bahwa minyak tersebut mempunyai aroma yang baik. Dari hasil analisis diperoleh bahwa minyak kilemo dari daun yang disuling dengan metode kukus secara visual mempunyai bilangan ester tertinggi, sedangkan minyak kilemo dari kulit batang yang disuling dengan metode rebus menghasilkan bilangan ester terendah.

Besarnya bilangan ester minyak kilemo dari daun yang disuling dengan metode kukus adalah 31.66, dan yang disuling dengan metode rebus 28.55. Sedangkan untuk minyak kilemo dari kulit batang yang disuling dengan metode kukus besarnya 18.74 dan yang disuling dengan metode rebus besarnya 17.6. Perbedaan nilai bilangan ester minyak kilemo hasil penyulingan daun dan kulit batang tumbuhan kilemo kemungkinan disebabkan karena perbedaan kandungan senyawa ester pada minyak. Dari pengamatan diperoleh bahwa minyak kilemo dari daun mempunyai aroma yang lebih segar bila dibandingkan aroma minyak dari kulit batang. Sifat aroma minyak ini dapat membuat tingginya bilangan ester pada minyak tersebut. 


\section{H. Komponen Kimia}

Dari analisis komponen kimia minyak kilemo asal kuningan Jawa Barat, diperoleh komponen utama minyak dari daun berupa senyawa sineol, sitronellol, $\alpha$ - pinen dan $\beta$ - pinen. Sedangkan komponen minyak dari kulit batang adalah senyawa sineol, limonen, sitronellol dan sitronellal (Gambar 1 dan 2).

Minyak kilemo hasil penyulingan daun mempunyai kandungan senyawa sineol dan sitronellol yang lebih tinggi bila dibandingkan dengan minyak kilemo hasil penyulingan kulit batang. Besarnya kadar senyawa sineol dan sitronellol dalam minyak kilemo hasil penyulingan daun adalah 59.24 dan 10.66. Sedangkan kadar senyawa sineol dan sitronellol dari minyak kilemo hasil penyulingan kulit batang adalah 17.27 dan 3.44 (Tabel 4 dan 5).

Komponen utama lain yang banyak terdapat dalam minyak dari daun adalah $\alpha$ pinen dan $\beta$ - pinen, sedangkan dalam minyak hasil penyulingan kulit batang adalah senyawa limonen dan sitronellal.

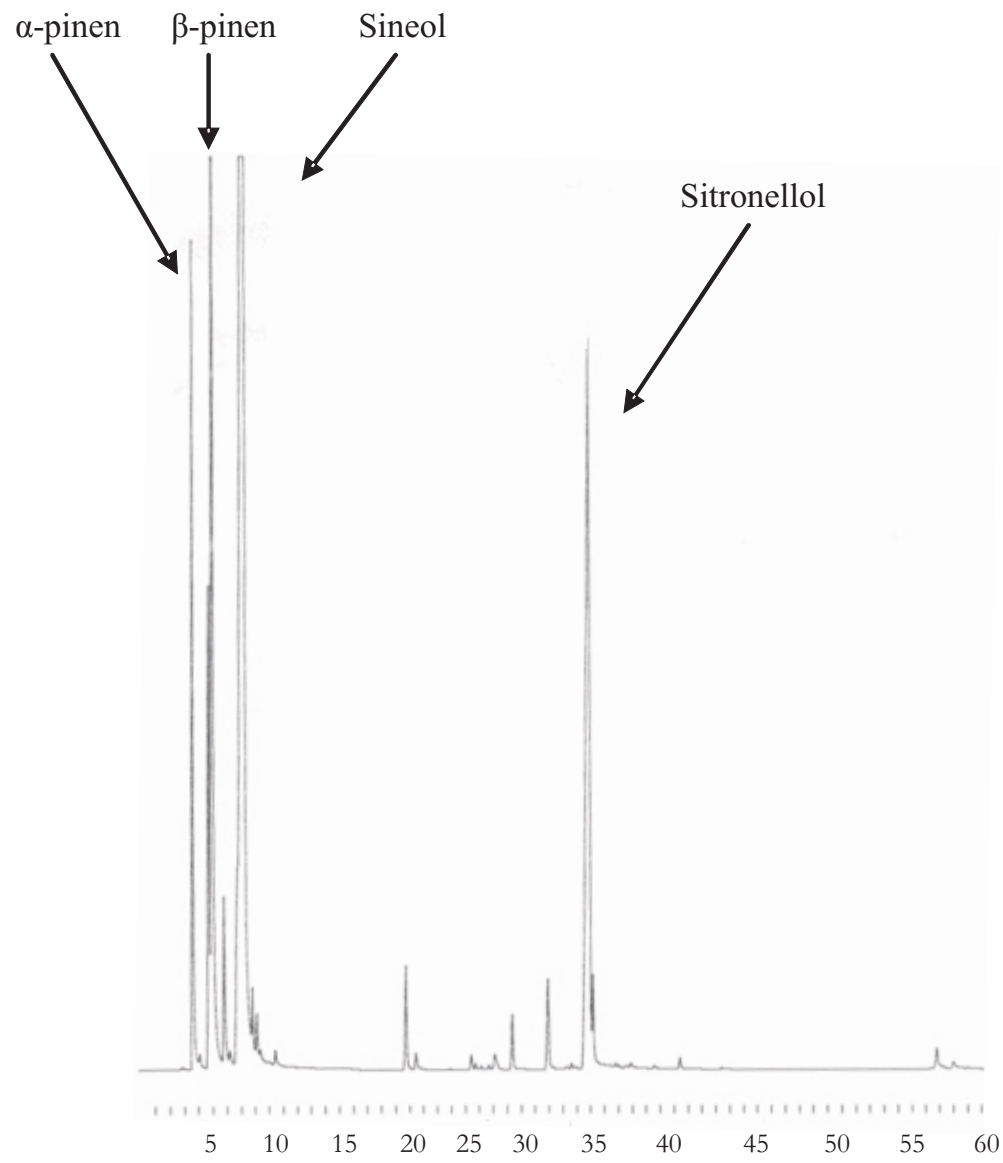

Gambar1. Profil kromatogram komponen kimia minyak dari daun kilemo Figure 1. Chromatogram profile of chemical component on kilemo oil from leaves 


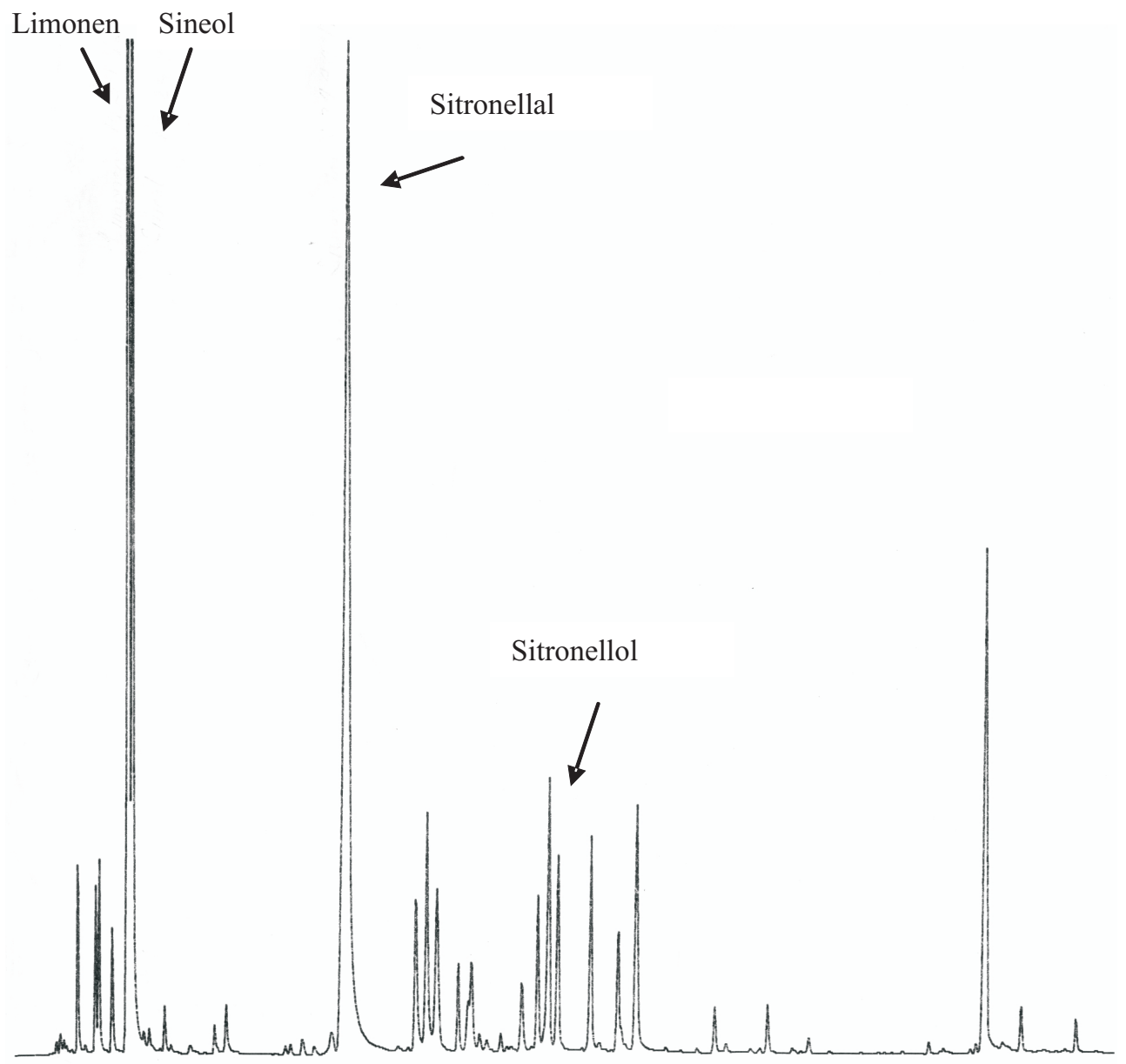

$\begin{array}{lllllllllllll}5 & 10 & 15 & 20 & 25 & 30 & 35 & 40 & 45 & 50 & 55 & 60 & 65\end{array}$

Gambar 2. Profil kromatogram komponen kimia minyak dari kulit batang kilemo Figure 2. Chromatogram profile of chemical component on kilemo oil from stem bark 


\section{KESIMPULAN}

1. Rendemen minyak kilemo hasil penyulingan daun, lebih tinggi bila dibandingkan dengan rendemen minyak hasil penyulingan kulit batang.

2. Minyak kilemo hasil penyulingan daun mempunyai berat jenis $0.9037-0.0982$, indeks bias $1.4617-1.4630$, putaran optik $-20^{\circ} 30^{\prime}-17^{\circ}$, Kelarutan dalam alkohol 1:1, bilangan asam 0.42 - 1.23 dan bilangan ester 25.79 - 31.32 .

3. Minyak kilemo hasil penyulingan dari kulit batang mempunyai berat jenis $0.8865-0.8895$, indeks bias 1.4607 - 1.4667, putaran optik $-16^{\mathrm{O}} 27^{\prime}-18^{\mathrm{O}} 54^{\prime}$ Kelarutan dalam alkohol 1:1, bilangan asam 1.64 - 4.83 dan bilangan ester 16.63 - 20.86 .

4. Komponen utama minyak kilemo hasil peyulingan daun adalah sineol, sitronellol, $\alpha$-pinen dan $\beta$-pinen, sedangkan komponen utama minyak kilemo hasil penyulingan dari kulit batang adalah sineol, sitronellol, limonen, dan sitronellal.

\section{DAFTAR PUSTAKA}

Besari, I., E. Sulistiowati dan M. Ishak. 1982. Kimia Organik. Armico. Bandung.

Boedhowie, S. Pranggonowati. 1983. Petunjuk Praktek Pengawasan Mutu Hasil Pertanian, Jilid II.. Direktorat Pendidikan Menengah Kejuruan, Departemen Pendidikan dan Kebudayaan. Jakarta.

Heyne, K. 1987. Tumbuhan Berguna Indonesia, Jilid II. Badan Litbang Kehutanan-Yayasan Sarana Wanajaya. Jakarta.

Jhun, Khun. 1992. The effect of composition of plant growth of Litsea species. The Macmillan Press Ltd. London.

Ketaren, S. 1985. Pengantar Teknologi Minyak Atsiri. Balai Pustaka. Jakarata.

Ketaren, S. 1997. Minyak atsiri bersumber dari daun. Agro Industri Press. IPB Bogor.

Sofyan, R., Ma'mun dan Anggraeni. 2000. Pemanfaatan tanaman Litsea sp. Balai Penelitian Tanaman Rempah dan Obat. Bogor.

Wiyono, B., Hartoyo dan Poedji Hastoeti. 2000. Sifat dasar minyak keruing dan kemungkinan penerapan baku mutunya. Buletin Penelitian Hasil Hutan. 18 (2) :123-135. Pusat Penelitian Hasil Hutan. Bogor. 